\title{
The Functional Variant in the 3'UTR of PTPRT with the Risk of Esophageal Squamous Cell Carcinoma in a Chinese Population
}

\author{
Yongliang Yao ${ }^{a}$ Jie Shao Jianhong Wu ${ }^{a}$ Qinghui Zhang ${ }^{a}$ Jianjun Wang ${ }^{a}$ \\ Daping Xiao ${ }^{b}$ Feng Huang ${ }^{a}$
}

aDepartment of clinical laboratory, The First People's Hospital of Kunshan, Affiliated Hospital of Jiangsu University, Affiliated to Jiangsu University, Kunshan, Jiangsu, 'bepartment of Clinical Laboratory, the $359^{\text {th }}$ Hospital of PLA, Zhengjiang, China

\section{Key Words}

Genotype $\cdot \operatorname{miR}-218 \cdot 3^{\prime}$-UTR $\cdot$ Tumor growth $・$ Metastasis

\begin{abstract}
Background/Aims: PTPRT is an essential tumor suppressor that plays crucial roles in regulating the mechanisms of tumorigenesis. Polymorphisms in PTPRT have been reported associated with human longevity, but their association with the risk of esophageal squamous cell carcinoma (ESCC) has not been found so far. In this study, we focused on the miRNAs associated SNPs in the 3'-UTR of PTPRT to investigate the further relationship of the SNPs with miRNAs among Chinese ESCC patients. Methods: We performed case-control study including 790 ESCC patients and 749 cancer-free controls. Genotyping, real time PCR assay, cell transfection and the dual luciferase reporter assay were used in our study. Results: We found that patients suffering from smoking exposure, drinking exposure and the history of cancer indicated to be the susceptible population by comparing with controls. Besides, SNP rs2866943 in PTPRT 3'-UTR was involved in the occurrence of ESCC by acting as a protective factor while rs6029959 acting a risk factor. SNP rs2866943 was also could be regulated by miR-218 which caused a down-regulation of PTPRT in patients with CT and TT genotype. Furthermore, the carriers of CT and TT genotype presented a small tumor size as well as the low probability of metastasis. Conclusion: Our findings have shown that the SNP rs 2866943 in PTPRT 3'-UTR, through disrupting the regulatory role of miR-218 in PTPRT expression, rs2866943 in PTPRT might act as a protective factor in the pathogenesis of ESCC.
\end{abstract}

Y.Yao, J. Shao contributed equally to this work.

Yao Yongliang, PhD,

KARGER 125
Department of Lab Medicine, The First People's Hospital of Kunshan, Affiliated Hospital of Jiangsu University, East Qianjin Road 91\#, Kunshan, Jiangsu 21530 (China)

Tel. + 860512 57534505, E-Mail Yaoyl313@163.com 


\begin{tabular}{|c|c|c|}
\hline Cellular Physiology & Cell Physiol Biochem 2015;36:306-314 & \\
\hline and Biochemistry & $\begin{array}{l}\text { DOI: 10.1159/000374073 } \\
\text { Published online: May 05, } 2015\end{array}$ & $\begin{array}{l}\text { O } 2015 \text { S. Karger AG, Basel } \\
\text { www.karger.com/cpb }\end{array}$ \\
\hline
\end{tabular}

\section{Introduction}

Esophageal carcinoma is one of the most deadly malignant tumors in the world. It has become the sixth leading cause of death and the eighth most frequently diagnosed cancer [1]. Esophageal carcinoma is divided into three types including squamous carcinoma (ESCC); adenocarcinoma and undifferentiated carcinoma based on pathological diagnosis [2]. ESCC is the most common subtype with a poor treatment and survive rate [3, 4]. Age, diet, genetic background and environmental factors are thought to be associated with risk of ESCC [5, 6]. Although many people are exposed to these risk factors, only a few individuals develop ESCC in their lifetimes, suggesting that genetic variation may contribute to esophageal carcinogenesis. Traditional treatment on ESCC including chemotherapy, radiation therapy and esophageal resection is not enough comparing with the increasing number of people suffering with ESCC [7-9]. Improving results with the candidate gene approach have led to its growing acceptance as a potentially useful method for investigating genetic risk factors for ESCC among Chinese.

Protein Tyrosine Phosphatase, Receptor type, T (PTPRO) is a member of the protein tyrosine phosphatase (PTP) family [10]. PTPs are known to be signaling molecules that regulate a variety of cellular processes including cell growth, differentiation, mitotic cycle, and oncogenic transformation [11]. This PTP possesses an extracellular region, a single transmembrane region, and two tandem intracellular catalytic domains, and thus represents a receptor-type PTP. The extracellular region contains a meprin-A5 antigen-PTP (MAM) domain, Ig-like and fibronectin type III-like repeats [12]. Recently researchers have identified a heterozygous c.4094C-T transition in the PTPRT gene, resulting in a thr1365-tomet (T1365M) substitution at a highly conserved residue in the second tyrosine phosphatase catalytic domain which was highly associated with the pathogenesis of cancer $[13,14]$. Wang et al. reported that the mutated tyrosine phosphatases are tumor suppressor genes, regulating cellular pathways that may be amenable to therapeutic intervention [15].

MiRNAs are small, non-coding RNA molecules of 19-25 nucleotides which have been reported to play important roles by regulating cell differentiation, proliferation, migration and apoptosis [16]. MiRNAs negatively regulate their target genes expression at the posttranscription level through binding to 3' untranslated regions (UTRs) of their targets message RNAs $[17,18]$. miRNAs could also regulate the 3'UTR region who harboured the single-nucleotide polymorphisms (SNPs), SNP, as the most common human genetic variations, have been proved to be significantly related to the occurrence of diseases including gastric cancer [19]. More and more studies have provided evidences that SNPs located in the miRNA (miRSNPs) binding sites through affecting the binding of miRNAs with the target genes resulted in reduction or increase in the target mRNA translation, and thus being associated with the susceptibility to cancers [20,21]. Researchers have found that the rs2910164 polymorphismin the sequence of miR-146a precursor may influence the susceptibility to gastric cancer in the Chinese population as well as SNPs rs4143815 and rs4819388 in the 3'UTRs of B7-H1 and B7-H2 genes were significantly related to the occurrence of gastric cancer [22-24].

In this study, we focused on the SNPs in the 3'UTR of PTPRT which has not been reported before. By using the bioinformatics software (http://www.bioguo.org/miRNASNP/), we obtained all the SNPs which could regulate by different miRNAs as candidate SNPs and further investigated the allele distribution in a case-control study.

\section{Materials and Methods}

Study subjects

The hospital-based case-control study consists of 790 patients newly diagnosed with ESCC and 749 cancer-free controls. All the subjects were genetically unrelated Han Chinese recruited from the the People's Hospital of Kunshan City, China between January 2007 and December 2012. Patients with other 


\section{Cellular Physiology Cell Physiol Biochem 2015;36:306-314 \begin{tabular}{l|l} 
DOI: 10.1159/000374073 & $\begin{array}{l}\text { O 2015 S. Karger AG, Basel } \\
\text { www.karger.com/cpb }\end{array}$ \\
\hline
\end{tabular} \\ Yao et al.: SNPs in PTPRT with ESCC}

hematological disorders, previous history of cancers, radiotherapy and chemotherapy were excluded. The cancer-free control subjects from the same geographic area showed no evidence of genetic relationship with the cases. The patients were classified according to World Health Organization classification. This study was approved by Ethics Committee of the First People's Hospital of Kunshan City, and every patient had written informed consent. The clinical feather of all the cases and controls were presented in Table1.

\section{Genotype}

We extracted genomic DNA from peripheral whole blood of every validation subject by using QIAamp DNA blood mini kits (Qiagen, Germany) according to the manufacturer's instructions. Genotyping was performed with the TaqMan SNP Genotyping Assay. The PCR reactions were carried out in a total volume of $5 \mu \mathrm{L}$ containing TaqMan Universal Master Mix, 80X SNP Genotyping AssayMix, Dnase-free water and 10-ng genomic DNA. The PCR conditions were $2 \mathrm{~min}$ at $50^{\circ} \mathrm{C}, 10 \mathrm{~min}$ at $95^{\circ} \mathrm{C}$, followed by 40 cycles at $95^{\circ} \mathrm{C}$ for 15 sec and $60^{\circ} \mathrm{C}$ for $1 \mathrm{~min}$. The 384-well ABI 7900HT Real Time PCR System

\section{Real time PCR assay}

Real time polymerase chain reaction (RT-PCR) was performed to determine whether the $\mathrm{C}$ to $\mathrm{T}$ mutation changed the expression level of PTPRT. The amplification conditions were $95^{\circ} \mathrm{C}$ for 10 minutes, followed by 40 cycles of $95^{\circ} \mathrm{C}$ for 30 seconds, $55^{\circ} \mathrm{C}$ for 40 seconds, and $72^{\circ} \mathrm{C}$ for 30 seconds, and finally $4{ }^{\circ} \mathrm{C}$ for 30 minutes for cooling.

\section{Cell lines and cell culture}

ESCC cell lines and TE-1 and Eca-109 were purchased from the Chinese Academy of Sciences Cell Bank. All cells were cultured in RPMI-1640 (Gibco, USA) supplemented with $10 \%$ fetal bovine serum (Invitrogen, Carlsbad, USA) and grown in humidified $5 \% \mathrm{CO} 2$ at $37^{\circ} \mathrm{C}$. MiR-16 mimics and normal control were obtained from Genepharma (Shanghai, China).The transfection was conducted by using Lipofectamine 2000 (Invitrogen Corp, CA, USA).

\section{Prediction of miRNAs binding to the SNP}

Bioinformatics analysis (http://www.bioguo.org/miRNASNP/) was used to predict the related SNPS in the 3'UTR of PTPRT which could be regulated by different miRNAs.

\section{Construction of luciferase-based reporter plasmids}

All the fragment of the 3'UTR containing either C or T allele was amplified. The PCR production was cloned into the pGL3-promoterless luciferase-based plasmid (Promega, CA, USA) at the cloning site between KpnI and XhoI. The amplified fragment was verified by DNA sequencing.

Dual-luciferase reporter assay

The 3'-UTR sequence of PTPRT predicted to interact with miR-218 or a mutated sequence with the predicted target sites were inserted into the KpnI and XhoI sites of pGL3 promoter vector (Genscript, Nanjing, China). For reporter assay, cells were plated onto 24-well plates and transfected with 100 ng of pGL3-PTPRT wild, pGL3-PTPRT mutant and miR-218 mimics, respectively by using Lipofectamine 2000 (Invitrogen Corp, CA, USA). A Renilla luciferase vector pRL-SV40 (5 ng) was also co-transfected to normalize the differences in transfection efficiency. Transfection was repeated three times in triplicate

\section{Statistical analysis}

The association between rs2866943 and rs6029959 genotypes and the risk of ESCC was evaluated by calculating the odds ratios (ORs) and their 95\% confidence intervals (CIs) using univariate and multivariate logistic regression analysis. Stratification analysis was performed according to the clinical characteristic and risk classification to determine the genotype distribution in cases and controls as well as their association with the risk of ESCC. The difference of the expression levels of PTPRT with three genotypes and the difference of the relative luciferase activities between the wild and mutant genotype were evaluated by independent-sample t test. All statistical tests were two-sided and $\mathrm{P}<0.05$ was considered statistically significant. Statistical analysis was performed with SPSS 13.0 (SPSS Ltd.) and SAS software (version 9.1.3; SAS Institute, Cary, NC, USA). The graphs were generated by Graphpad Prism 5.0 (Graphpad Software, Inc.). 


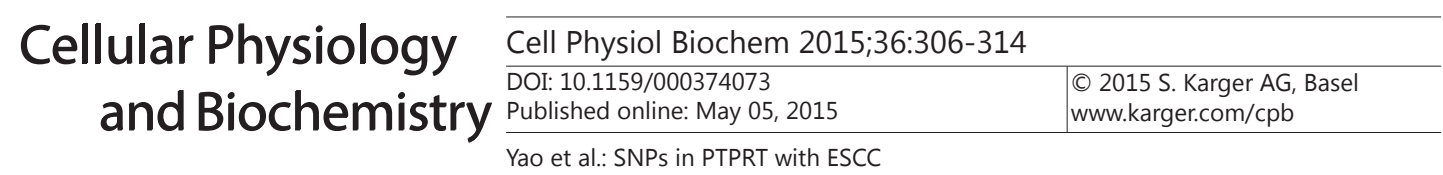

Table 1. Frequency distributions of selected variables in patients and cancer-free controls. *Two-sided chi-square test for either genotype distributions or allele frequencies between cases and controls

\begin{tabular}{|c|c|c|c|c|c|}
\hline \multirow{2}{*}{ Variables } & \multicolumn{2}{|c|}{ Cases $(n=790)$} & \multicolumn{2}{|c|}{ Controls $(n=749)$} & \multirow{2}{*}{$P^{*}$} \\
\hline & $N$ & $\%$ & $N$ & $\%$ & \\
\hline \multicolumn{6}{|c|}{ Age (years) } \\
\hline$\leq 60$ & 431 & 54.6 & 411 & 54.9 & 0.901 \\
\hline$>60$ & 359 & 45.4 & 338 & 45.1 & \\
\hline \multicolumn{6}{|l|}{ Gender } \\
\hline Male & 449 & 56.8 & 442 & 59.0 & 0.387 \\
\hline Female & 341 & 43.1 & 307 & 40.9 & \\
\hline \multicolumn{6}{|c|}{ Smoking exposure } \\
\hline Negative & 216 & 27.3 & 422 & 56.4 & 0.030 \\
\hline Positive & 574 & 72.7 & 327 & 43.6 & \\
\hline \multicolumn{6}{|c|}{ Drinking exposure } \\
\hline Negative & 248 & 31.4 & 521 & 69.6 & $<0.001$ \\
\hline Positive & 542 & 68,6 & 228 & 30.4 & \\
\hline \multicolumn{6}{|c|}{ Family history of cancer } \\
\hline Negative & 373 & 47.2 & 411 & 54.9 & 0.003 \\
\hline Positive & 417 & 52.8 & 338 & 45.1 & \\
\hline
\end{tabular}

\section{Results}

Subject characteristics

The characteristics of the 790 ESCC patients and 749 healthy controls are summarized in Table 1. No statistically significant differences were observed between cases and controls in terms of sex and age (both $P>0.05$ ). Patients suffering from smoking exposure, drinking exposure and the history of cancer indicated to be the susceptible population by comparing with controls.

The miRSNPs in the PTPRT gene 3'-UTR

In order to investigate the miRNA associated SNPs in the 3'UTR of PTPRT, we first found all the SNPs from the SNP databases NCBI db SNP BUILED 129 and ENSEMBL v58 in the 3'UTR of PTPRT gene with the minor allele frequency(MAF) $>0.05$. We then used bioinformatic softwares Diana-Micro, MicroInspector, miR-anda, miRNAMap, RNAhybrid to predict miRNAs that can bind to the PTPRT 3'-UTR. The miRNASNP database was also applied to explore the miRNAs which could also bind to the 3'-UTR of patients harbored the SNP. As shown in Table 2. Finally, we obtained 23 SNPs in the 3'UTR which could be regulated by different miRNAs. The positions of the SNPs in PTPRT as well as the variants were listed. Further genotyping was performed to detect the distribution of allele gene of the 23 SNPs in our research.

Correlation of rs2866943 and rs6029959 with gastric cancer

We detected all the 23 SNPs genotype frequencies in 790 ESCC cases and 749 controls. Only two SNPs (rs2866943 and rs6029959) indicated a significant difference in ESCC patients with the T-allele carriers and C-allele carrier, respectively; however, the other SNPs presented no difference (data not shown). As listed in Table3, Chi-square statistical analysis results showed that the genotypes of rs2866943 were in Hardy-Weinberg equilibrium distribution pattern in the healthy control group $(\mathrm{P}=0.42)$. Further, logistic regression analysis results revealed that The CT genotype and TT genotype presented a significant dereased risk of ESCC 


\begin{tabular}{|c|c|c|}
\hline Cellular Physiology & Cell Physiol Biochem 2015;36:306-314 & \\
\hline and Biochemistry & $\begin{array}{l}\text { DOI: 10.1159/000374073 } \\
\text { Published online: May 05, } 2015\end{array}$ & $\begin{array}{l}\text { O } 2015 \mathrm{~S} \text {. Karger AG, Basel } \\
\text { www.karger.com/cpb }\end{array}$ \\
\hline
\end{tabular}

Table 2. SNPs located in the PTPRT gene 3'UTR and the predicted miRNAs. Chr = chromosome; UTR= Untranslated Regions

as compared with the CC genotype. Besides, the $T$ carrier also indicated an increased risk ( $\mathrm{P}=0.015)$. The PTPRO rs6029959 C allele was also shown to be a risk allele. Logistic regression analyses indicated that individuals with the rs6029959 AC genotype was significantly associated with gastric cancer risk $(\mathrm{OR}=1.50,95 \% \mathrm{CI}=1.24$ 2.99; $\mathrm{P}=0.0001)$. Individuals having the rs6029959 CC genotype had an OR of 2.47 (95 \% CI=1.05-1.32; $\mathrm{P}=0.0001$ ) for ESCC compared with individuals having the rs6029959 AA genotype. All ORs were adjusted for sex, age, and smoking status, drinking history or family cancer history.

\section{The effect of rs2866943 and rs6029959 on the regulatory role of miRNAs in PTPRT expression} Since the SNP rs2866943 and rs6029959 were predicted to locate in the binding site of miR-218 and miR-142-5p, respectively. We hypothesized that the expression of PTPRT might be regulated by these miRNAs, which can be impacted

\begin{tabular}{|c|c|c|c|c|}
\hline SNP & chr & $\begin{array}{l}\text { 3'UTR } \\
\text { position }\end{array}$ & $\begin{array}{l}\text { Associated } \\
\text { miRnA }\end{array}$ & Allele* \\
\hline rs1065155 & 20 & $3145-3165$ & miR-874 & $\mathrm{A} / \mathrm{G}$ \\
\hline rs112700109 & 20 & $3341-3360$ & $\operatorname{miR}-2110$ & $\mathrm{C} / \mathrm{T}$ \\
\hline rs113281274 & 20 & $1338-1363$ & miR-1262 & $\mathrm{A} / \mathrm{C}$ \\
\hline rs114291605 & 20 & $1338-1363$ & miR-140-3p & $\mathrm{T} / \mathrm{G}$ \\
\hline rs116838271 & 20 & $8050-8074$ & miR-574 & $\mathrm{A} / \mathrm{C}$ \\
\hline rs2664587 & 20 & 6616-6637 & miR-3694 & $\mathrm{C} / \mathrm{T}$ \\
\hline rs2866943 & 20 & $6693-6710$ & miR-218 & $\mathrm{C} / \mathrm{T}$ \\
\hline rs3787281 & 20 & $1622-1642$ & miR-26a/b & $\mathrm{A} / \mathrm{G}$ \\
\hline rs3787282 & 20 & 3564-3586 & miR-1297 & $\mathrm{A} / \mathrm{G}$ \\
\hline rs41278132 & 20 & 5376-5397 & miR-3180 & $\mathrm{C} / \mathrm{T}$ \\
\hline rs 45474194 & 20 & $6699-6724$ & miR-1321 & $\mathrm{A} / \mathrm{G}$ \\
\hline rs55683344 & 20 & $3630-3648$ & miR-876-3p & $\mathrm{C} / \mathrm{T}$ \\
\hline rs60102878 & 20 & $1160-1181$ & miR-1291 & $\mathrm{A} / \mathrm{G}$ \\
\hline rs6029959 & 20 & $2465-2488$ & miR-142-5p & $\mathrm{A} / \mathrm{C}$ \\
\hline rs6072621 & 20 & $4835-4855$ & miR-3153 & $\mathrm{A} / \mathrm{G}$ \\
\hline rs6102660 & 20 & $596-618$ & miR-431/942 & $\mathrm{C} / \mathrm{T}$ \\
\hline rs6102662 & 20 & 6474-6499 & miR-548a & $\mathrm{C} / \mathrm{G}$ \\
\hline rs6102663 & 20 & $3654-3679$ & miR-361-5p & $\mathrm{A} / \mathrm{G}$ \\
\hline rs67506870 & 20 & 1789-1811 & miR-3928 & $\mathrm{A} / \mathrm{G}$ \\
\hline rs73119823 & 20 & $731-752$ & miR-3154 & $\mathrm{G} / \mathrm{T}$ \\
\hline rs73269502 & 20 & $3107-3129$ & miR-345 & $\mathrm{A} / \mathrm{G}$ \\
\hline rs7352413 & 20 & $4245-4270$ & miR-3656 & $\mathrm{G} / \mathrm{T}$ \\
\hline rs73907079 & 20 & $1105-1121$ & $\mathrm{miR}-30 \mathrm{a} / \mathrm{b} / \mathrm{c} / \mathrm{d}$ & $\mathrm{C} / \mathrm{G}$ \\
\hline
\end{tabular}
by rs2866943 or rs6029959. To test whether or not the inhibitory role of these miRNAs impacted by the two SNPs, we first detected the expression level of PTPRT expression level in patients harbored the CC, CT and TT genotypes as well as the patients with AA, AC and CC genotypes. We found that patients with CT or TT genotypes presented a decreased level of PTPRT by comparing with the patients with CC genotype; however there was no difference in rs6029959 (Fig. 1A and 2A). We then constructed pGL3 vectors including the allelespecific binding sequences, and then co-transfected it with miR-218 or miR-142-5p as well as the controls in ESCC cell lines including TE-1 and Eca109 (Fig. 1B and 2B). As presented in Figure1C, D and 2C, D, we found that the expression of T-allele-specific pGL3 construct was significantly suppressed by miR-218 $(\mathrm{P}=0.003)$. However, the expression of $\mathrm{C}$-allele-specific pGL3 construct was not inhibited by miR-142-5p ( $\mathrm{P}=0.324)$. These findings suggested that the inhibitory affection of the TT or CT genotype of PTPRT might be regulated by miR-218.

Stratified analyses of association between PTPRT polymorphism and ESCC risk

Then, we did stratified analysis of the association of the rs2866943 genotypes with the clinicopathological parameters of ESCC (Table 4). We found a significant association of the 
Table 3. Genotype frequencies of the PTPRT rs 2866943 and rs6029959 polymorphism among ESCC cases and controls. ${ }^{a}$ The ORs, $95 \%$ CIs and $P$ value were calculated after adjusting for age, gender, parental smoking, drinking and family caner history

\begin{tabular}{|c|c|c|c|c|c|c|}
\hline \multirow{2}{*}{ Genotype } & \multicolumn{2}{|c|}{ Cases $(n=790)$} & \multicolumn{2}{|c|}{ Controls $(n=749)$} & \multirow{2}{*}{$\begin{array}{c}\text { OR } \\
(95 \% \mathrm{CI})^{\mathrm{a}}\end{array}$} & \multirow{2}{*}{$P$ Value $^{\mathrm{a}}$} \\
\hline & $N$ & $\%$ & $N$ & $\%$ & & \\
\hline \multicolumn{7}{|c|}{ rs2866943 } \\
\hline CC & 374 & 47.4 & 401 & 53.5 & 1.00 & 0.0001 \\
\hline CT & 328 & 41.5 & 324 & 43.3 & $0.78(1.20-1.72)$ & \\
\hline TT & 88 & 11.1 & 24 & 3.2 & $0.93(1.11-1.94)$ & \\
\hline $\mathrm{T}$ carrier & 416 & 52.7 & 348 & 46.5 & $0.82(1.32-1.53)$ & 0.015 \\
\hline \multicolumn{7}{|c|}{ rs6029959 } \\
\hline $\mathrm{AA}$ & 355 & 45.0 & 422 & 56.4 & 1.00 & 0.0001 \\
\hline $\mathrm{AC}$ & 381 & 48.2 & 301 & 40.2 & $1.50(1.24-1.99)$ & \\
\hline CC & 54 & 6.8 & 26 & 3.4 & $2.47(1.05-1.32)$ & \\
\hline C carrier & 435 & 55.0 & 327 & 43.6 & $1.58(1.12-1.53)$ & 0.0001 \\
\hline
\end{tabular}

Table 4. Stratified analysis of rs2866943 genotype with clinicopathological parameters of ESCC. *Two-sided chi-square test for either genotype distributions or allele frequencies between cases and controls

\begin{tabular}{|c|c|c|c|c|c|c|c|}
\hline \multirow{2}{*}{ Feather } & \multicolumn{4}{|c|}{ Genotype } & \multirow{2}{*}{$\begin{array}{l}\text { CT vs CC } \\
P \text { Value }\end{array}$} & \multirow{2}{*}{$\begin{array}{l}\text { TT vs CC } \\
P \text { Value }\end{array}$} & \multirow{2}{*}{$\begin{array}{l}\mathrm{T} \text { carrier vs } \mathrm{CC} \\
P \text { Value }\end{array}$} \\
\hline & CC & CT & TT & $\mathrm{T}$ carrier & & & \\
\hline \multicolumn{8}{|l|}{ Age (years) } \\
\hline$\leq 60$ & 204 & 179 & 48 & 227 & 0.99 & 1.00 & 0.99 \\
\hline$>60$ & 170 & 149 & 40 & 189 & & & \\
\hline \multicolumn{8}{|l|}{ Gender } \\
\hline Male & 202 & 194 & 53 & 247 & 0.17 & 0.29 & 0.13 \\
\hline Female & 172 & 134 & 35 & 169 & & & \\
\hline \multicolumn{8}{|c|}{ Differentiation grade } \\
\hline Well & 186 & 159 & 43 & 202 & 0.91 & 0.97 & 0.90 \\
\hline Moderate & 124 & 109 & 29 & 138 & & & \\
\hline Poorly & 64 & 60 & 16 & 76 & & & \\
\hline \multicolumn{8}{|c|}{ Tumor Size $(\mathrm{cm})$} \\
\hline$\leq 3 \mathrm{~cm}$ & 172 & 226 & 55 & 281 & 0.001 & 0.005 & 0.001 \\
\hline$>3 \mathrm{~cm}$ & 202 & 102 & 33 & 135 & & & \\
\hline \multicolumn{8}{|c|}{ Tumor Number } \\
\hline Solitary & 191 & 160 & 41 & 201 & 0.66 & 0.45 & 0.52 \\
\hline Multiple & 183 & 164 & 47 & 211 & & & \\
\hline \multicolumn{8}{|c|}{ Tumor Capsular } \\
\hline Incomplete & 201 & 192 & 49 & 241 & 0.20 & 0.74 & 0.24 \\
\hline Complete & 173 & 136 & 39 & 175 & & & \\
\hline \multicolumn{8}{|l|}{ Metastasis } \\
\hline Yes & 290 & 136 & 29 & 165 & 0.001 & 0.001 & 0.001 \\
\hline No & 84 & 192 & 59 & 251 & & & \\
\hline
\end{tabular}

rs2866943 genotypes with the tumor size, and tumor metastasis,. Compared with the CC homozygote, the carriers of CT and TT genotype presented a small tumor size as well as the low probability of metastasis.

\section{Discussion}

In the present study, we investigated the relationship between miRSNPs within the 3'UTR of PTPRT gene and the risk of ESCC. We observed that PTPRT rs2866943 CT or TT genotype is associated with significantly decreased ESCC risk compared with CC genotype and the increased risk of CC and AC genotypes comparing with AA genotype of SNP rs6029959. 


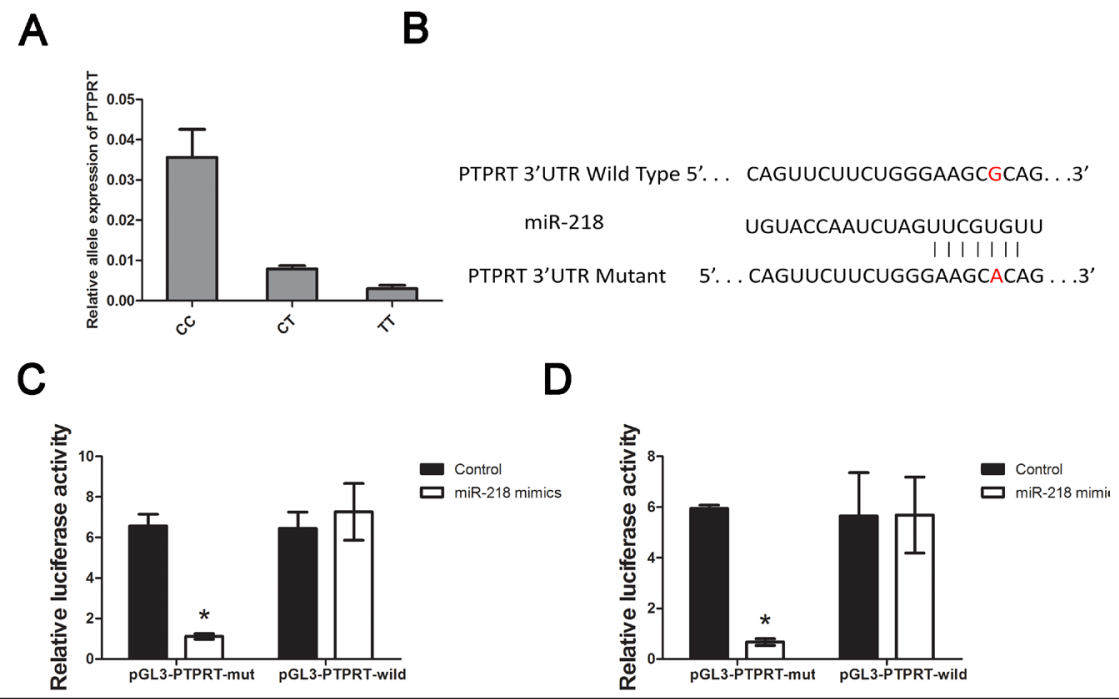

Fig. 1. Suppression of PTPRT of patients with CT/TT genotypes of SNP rs2866943 was regulated by miR218. A: The expression level of PTPRT was determined by RT-PCR in patients with CC, CT and TT genotypes. B: Bioinformatics predicted the binding site between the miR-218 with PTPRT and the mutation types were conducted into the pGL3 plasmid as presented. C, D: Cells were co-transfected with miR-218 mimics or control, Renilla luciferase vector pRL-SV40 for $48 \mathrm{~h}$. Both firefly and Renilla luciferase activities were measured in the same sample. Firefly luciferase signals were normalized with Renilla luciferase signals. Left panel indicated the TE-1 cell line (panel C) while the right indicated Eca109 (panel D) cell lines. Data was presented as the mean \pm SEM. $*$ indicates a significant difference $(\mathrm{P}<0.05)$.

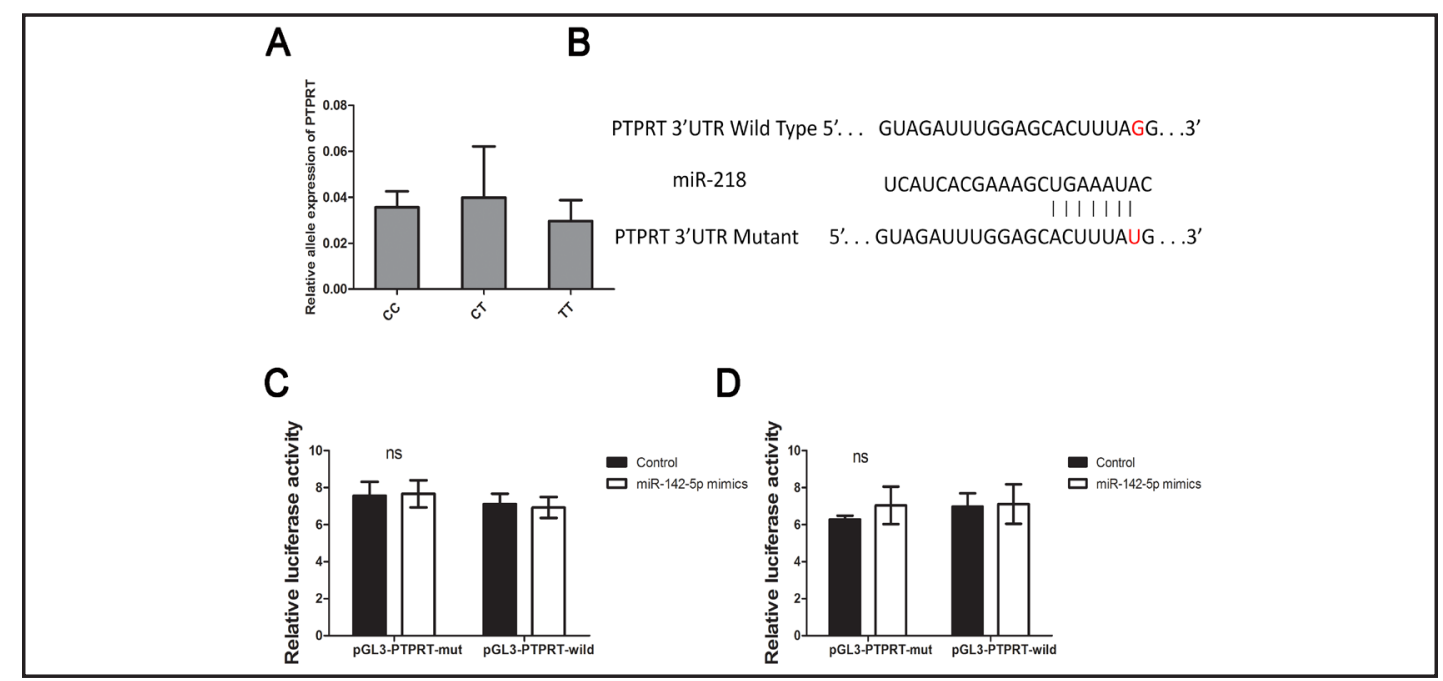

Fig. 2. MiR-142-5p could not regulated the the 3'UTR of PTPRT with SNP rs6029959. A: The expression level of PTPRT was determined by RT-PCR in patients with AA, AC and CC genotypes. B: Bioinformatics predicted the binding site between the miR-142-5p with PTPRT and the mutation types were conducted into the pGL3 plasmid as presented. C, D: Cells were co-transfected with miR-142-5p mimics or control, Renilla luciferase vector pRL-SV40 for $48 \mathrm{~h}$. Both firefly and Renilla luciferase activities were measured in the same sample. Firefly luciferase signals were normalized with Renilla luciferase signals. Left panel indicated the TE-1 cell line (panel C) while the right indicated Eca109 cell lines (panel D). Data was presented as the mean \pm SEM. * indicates a significant difference $(\mathrm{P}<0.05)$.

We further found that the SNP rs2866943, locating in the binding sites of miR-218 through disrupting the inhibitory role of miR-218 on PTPRT expression, played an important role in the development of ESCC. 


\begin{tabular}{|c|c|c|}
\hline Cellular Physiology & Cell Physiol Biochem 2015;36:306-314 & \\
\hline and Biochemistry & $\begin{array}{l}\text { DOI: 10.1159/000374073 } \\
\text { Published online: May 05, } 2015\end{array}$ & $\begin{array}{l}\text { O } 2015 \text { S. Karger AG, Basel } \\
\text { www.karger.com/cpb }\end{array}$ \\
\hline
\end{tabular}

Protein tyrosine phosphatases (PTPs) are known to be signaling molecules that regulate a variety of cellular processes including differentiation, cell proliferation, mitotic cycle and oncogenic transformation [25]. Emerging evidence has revealed that mutations in PTPs play vital roles in tumorigenesis [26]. PTPRT, also known as PTP $\rho$, is a member of the PTPs family. Recently, it has been reported that PTPRT is the most frequently mutated PTP gene in colorectal cancers (CRCs). PTPRT normally acts as a tumor suppressor and over-expression of PTPRT inhibits CRC cell growth [15]. It has been also reported that PTPRT knockout mice are highly susceptible to carcinogen azoxymethane-induced colon tumor [15]. Considering about the tumor suppressor gene function of PTPRT, our founding indicated that the $\mathrm{C}>\mathrm{T}$ SNP might be acted as protective factor in the pathogenesis of ESCC, however, the CT and TT genotypes could be down-regulated by miR-218. Numerous microRNAs have been reported to be associated in cancers; however, the consequence of miRNA deregulation in cancer is still unknown for many miRNAs [27]. As for the miRNAs focused in this study, miR-218 expression was found to be increased in multiple cancers. Increased miR-218 was associated with tumor growth and metastasis which was consistent with our results [28, 29].

In summary, we reported the first evidence that the SNP rs2866943 in PTPRT 3'-UTR was involved in the occurrence of ESCC by acting as a protective factor while rs6029959 acting a risk factor. SNP rs2866943 was also could be regulated by miR-218 which caused a down-regulation of PTPRT in patients with CT and TT genotype. This SNP was also found to be related to the clinicopathological features of ESCC, suggesting it may have important roles in preventing tumor development. Our results support the hypothesis that genetic variants interrupting miRNAs mediated regulation tumor suppressors would be involved in esophageal cancer etiology.

\section{Acknowledgement}

This work was supported by the Social Development Foundation of Kunshan (No. KS1130 to YY), Medical science and technology innovation project of Nanjing Military Region (NO.14ZD24 to XD).

\section{Disclosure Statement}

None declared.

\section{References}

1 Li W, Zheng J, Deng J, You Y, Wu H, Li N, Lu J, Zhou Y: Increased levels of the long intergenic nonprotein coding rna pou3f3 promote DNA methylation in esophageal squamous cell carcinoma cells. Gastroenterology 2014;146:1714-1726, e1715.

2 Kong KL, Kwong DL, Chan TH, Law SY, Chen L, Li Y, Qin YR, Guan XY: Microrna-375 inhibits tumour growth and metastasis in oesophageal squamous cell carcinoma through repressing insulin-like growth factor 1 receptor. Gut 2012;61:33-42.

3 Subramanyam D, Lamouille S, Judson RL, Liu JY, Bucay N, Derynck R, Blelloch R: Multiple targets of mir302 and mir-372 promote reprogramming of human fibroblasts to induced pluripotent stem cells. Nat Biotechnol 2011;29:443-448.

4 Qin YR, Tang H, Xie F, Liu H, Zhu Y, Ai J, Chen L, Li Y, Kwong DL, Fu L, Guan XY: Characterization of tumorsuppressive function of sox6 in human esophageal squamous cell carcinoma. Clin Cancer Res 2011;17:4655.

5 Vinci S, Gelmini S, Pratesi N, Conti S, Malentacchi F, Simi L, Pazzagli M, Orlando C: Genetic variants in mir146a, mir-149, mir-196a2, mir-499 and their influence on relative expression in lung cancers. Clin Chem Lab Med 2011;49:2073-2080.

6 Wang H, Zhang P, Chen W, Feng D, Jia Y, Xie LX: Evidence for serum mir-15a and mir-16 levels as biomarkers that distinguish sepsis from systemic inflammatory response syndrome in human subjects. Clin Chem Lab Med 2012;50:1423-1428. 


\section{Cellular Physiology Cell Physiol Biochem 2015;36:306-314 \begin{tabular}{l|l|l}
\hline DOI: 10.1159/000374073 & (C)15 S. Karger AG, Basel
\end{tabular} and Biochemistry Published online: May 05, 2015 \\ Yao et al.: SNPs in PTPRT with ESCC}

7 Hirajima S, Komatsu S, Ichikawa D, Takeshita H, Konishi H, Shiozaki A, Morimura R, Tsujiura M, Nagata H, Kawaguchi T, Arita T, Kubota T, Fujiwara H, Okamoto K, Otsuji E: Clinical impact of circulating mir-18a in plasma of patients with oesophageal squamous cell carcinoma. Br J Cancer 2013;108:1822-1829.

8 Wang ZW, Zhang W, Dong W, Li BS, Mu DB, Huang W, Zhang J, Li HS, Zhang ZC, Lin HQ, Yi Y: Pathological analysis of extracapsular extension of metastatic lymph node and its potential impact on nodal clinical target volume in the radiotherapy of esophageal squamous cell carcinoma. Neoplasma 2014;61:324-330.

9 Zhu Y, Xia Y, Niu H, Chen Y: Mir-16 induced the suppression of cell apoptosis while promote proliferation in esophageal squamous cell carcinoma. Cell Physiol Biochem 2014;33:1340-1348.

10 Besco JA, Frostholm A, Popesco MC, Burghes AH, Rotter A: Genomic organization and alternative splicing of the human and mouse rptprho genes. BMC Genomics 2001;2:1.

11 Zhang P, Becka S, Craig SE, Lodowski DT, Brady-Kalnay SM, Wang Z: Cancer-derived mutations in the fibronectin iii repeats of ptprt/ptprho inhibit cell-cell aggregation. Cell Commun Adhes 2009;16:146-153.

12 McAndrew PE, Frostholm A, White RA, Rotter A, Burghes AH: Identification and characterization of rptp rho, a novel rptp $\mathrm{mu} /$ kappa-like receptor protein tyrosine phosphatase whose expression is restricted to the central nervous system. Brain Res Mol Brain Res 1998;56:9-21.

13 Lee JW, Jeong EG, Lee SH, Nam SW, Kim SH, Lee JY, Yoo NJ: Mutational analysis of ptprt phosphatase domains in common human cancers. APMIS 2007;115:47-51.

14 Yu J, Becka S, Zhang P, Zhang X, Brady-Kalnay SM, Wang Z: Tumor-derived extracellular mutations of ptprt / ptprho are defective in cell adhesion. Mol Cancer Res 2008;6:1106-1113.

15 Wang Z, Shen D, Parsons DW, Bardelli A, Sager J, Szabo S, Ptak J, Silliman N, Peters BA, van der Heijden MS, Parmigiani G, Yan H, Wang TL, Riggins G, Powell SM, Willson JK, Markowitz S, Kinzler KW, Vogelstein B, Velculescu VE: Mutational analysis of the tyrosine phosphatome in colorectal cancers. Science 2004;304:1164-1166.

16 Plasterk RH: Micro rnas in animal development. Cell 2006;124:877-881.

17 Valastyan S, Reinhardt F, Benaich N, Calogrias D, Szasz AM, Wang ZC, Brock JE, Richardson AL, Weinberg RA: A pleiotropically acting microrna, mir-31, inhibits breast cancer metastasis. Cell 2009;137:1032-1046.

18 Hyun S, Lee JH, Jin H, Nam J, Namkoong B, Lee G, Chung J, Kim VN: Conserved microrna mir-8/mir-200 and its target ush/fog2 control growth by regulating pi3k. Cell 2009;139:1096-1108.

19 Wang K, Diskin SJ, Zhang H, Attiyeh EF, Winter C, Hou C, Schnepp RW, Diamond M, Bosse K, Mayes PA, Glessner J, Kim C, Frackelton E, Garris M, Wang Q, Glaberson W, Chiavacci R, Nguyen L, Jagannathan J, Saeki N, Sasaki H, Grant SF, Iolascon A, Mosse YP, Cole KA, Li H, Devoto M, McGrady PW, London WB, Capasso M, Rahman N, Hakonarson H, Maris JM: Integrative genomics identifies lmo1 as a neuroblastoma oncogene. Nature 2011;469:216-220.

20 Bartel DP: Micrornas: Genomics, biogenesis, mechanism, and function. Cell 2004;116:281-297.

21 Wang Y, Zhou L, Chen J, Li J, He L, Wu P, Wang M, Tong N, Zhang Z, Fang Y: Association of the 3'utr foxo3a polymorphism rs4946936 with an increased risk of childhood acute lymphoblastic leukemia in a chinese population. Cell Physiol Biochem 2014;34:325-332.

22 Wu D, Wang F, Dai WQ He L, Lu J, Xu L, Guo CY: The mir-146a rs2910164 g > c polymorphism and susceptibility to digestive cancer in chinese. Asian Pac J Cancer Prev 2013;14:399-403.

23 Wang W, Li F, Mao Y, Zhou H, Sun J, Li R, Liu C, Chen W, Hua D, Zhang X: A mir-570 binding site polymorphism in the b7-h1 gene is associated with the risk of gastric adenocarcinoma. Hum Genet 2013;132:641-648.

24 Yang P, Tang R, Zhu J, Zou L, Wu R, Zhou H, Mao Y, Li R, Hua D, Wang W, Zhang H: A functional variant at mir24 binding site in b7-h2 alters susceptibility to gastric cancer in a chinese han population. Mol Immunol 2013;56:98-103.

25 Hendriks WJ, Elson A, Harroch S, Pulido R, Stoker A, den Hertog J: Protein tyrosine phosphatases in health and disease. FEBS J 2013;280:708-730.

26 Qi J, Li N, Fan K, Yin P, Zhao C, Li Z, Lin Y, Wang L, Zha X: Beta1,6 glcnac branches-modified ptprt attenuates its activity and promotes cell migration by stat3 pathway. PLoS One 2014;9:e98052.

27 Sagdeev RZ: The rise and fall of mir. Science 2001;291:1663.

28 Alajez NM, Lenarduzzi M, Ito E, Hui AB, Shi W, Bruce J, Yue S, Huang SH, Xu W, Waldron J, O'Sullivan B, Liu FF: Mir-218 suppresses nasopharyngeal cancer progression through downregulation of survivin and the slit2-robo1 pathway. Cancer Res 2011;71:2381-2391.

29 Small EM, Sutherland LB, Rajagopalan KN, Wang S, Olson EN: Microrna-218 regulates vascular patterning by modulation of slit-robo signaling. Circ Res 2010;107:1336-1344. 